\title{
Plant Defense Responses Coming To Shape
}

\author{
Chian Kwon* \\ Department of Molecular Biology, BK21 Graduate Program for RNA Biology, Dankook University, Jukjeondong 126, Yongin \\ 448-701, Korea
}

(Received on January 17, 2010; Accepted on March 9, 2010)

\begin{abstract}
Although still poorly understood, accumulating evidence clearly supports that plants also have a good immune system which have been developed and acquired during the evolution. The lack of specific mobile immune cells like a $B$ or $T$ cell in plants additionally suggests that most plant cells have capacity for defending themselves against numerous pathogens. Rapidly growing advances in understanding plant defense responses implicate that plant and animal immune responses are evolutionarily convergent although their origins are thought to be different. On the basis of recent findings, here current understanding of plant defense responses will be discussed.
\end{abstract}

\section{Keywords : PAMP, PRR, SAR, VAMP, WRKY}

Precise activation of immune responses in host organisms relies on the detection of attempting pathogens. This pathogen detection is dependent on the recognition of pathogenderived nonself molecules by host receptors. A pathogenassociated molecular pattern (PAMP) defines an evolutionarily conserved structural unit present only on/in a pathogen species. Although pathogens have additional pathogen-only molecules called effectors, a marked difference is the conservation of a PAMP but not an effector within a species. Host cells utilize a variety of surface or intracellular receptors called pattern recognition receptors (PRRs) to recognize PAMPs. The successful recognition of a PAMP by a cognate PRR then directly or indirectly initiates defense signaling via its signaling module such as a protein kinase domain or a protein kinase-recruiting motif, and in the end enables a host cell to repel the attacking pathogens (Boller and He, 2009).

It is now generally believed that plant cells also use various PRRs to detect pathogens by recognizing PAMPs. In Arabidopsis, so far three PRRs have been identified. FLS2 recognizes bacterial flagellin (Gomez-Gomez and Boller, 2000; Zipfel et al., 2004) (Fig. 1). It was originally

\footnotetext{
*Corresponding author.

Phone) +82-31-80053269, FAX) +82-31-80053191

E-mail)chiank@dankook.ac.kr
}

identified by screening Arabidopsis mutants that are insensitive to the active flagellin fragment, flg22 that arrests the plant growth (Gomez-Gomez and Boller, 2000). Although the introduction of wild-type (WT) FLS2 gene into the mutant plants restores the sensitiveness to flg22, it took however several years to identify its role in resistance to bacterial pathogens. Many plant pathologists are introducing bacteria directly into plant tissues by using a syringe or vacuum. But this kind of bacterial inoculation method is artificial, because in nature bacteria enter the plant tissue through stomata or wound sites. By mimicking the natural inoculation by spraying bacterial suspension onto the leaves, it was found that FLS2 plays a role in limiting bacterial growth in the plant tissues by in part restricting bacterial entry (Zipfel et al., 2004). The FLS2associated stomatal closure was recently shown to be required for Arabidopsis resistance to bacterial pathogens, because the pathogenic bacterium Pseudomonas syringae DC3000 produces and uses a polyketide toxin, coronatine for re-opening the closed stomata to enter the plant tissues (Melotto et al., 2006).

The second PRR identified in Arabidopsis is the EFR that recognizes bacterial elongation factor Tu (EF-Tu) (Zipfel et al., 2006) (Fig. 1). Although it is still unclear how the intracellular EF-Tu functions as a PAMP to be recognized by the surface PRR, reports that EF-Tu was found at cell surface in Mycoplasma pneumoniae and Lactobacillus johnsonii suggest its possible activity as a PAMP (Dallo et al., 2002; Granato et al., 2004). Unlike Arabidopsis, Nicotiana benthamiana is not able to respond to EF-Tu indicating failed acquisition of or mutation in EFR gene during the evolution in $N$. benthamiana (Kunze et al., 2004). However, the acquired responsiveness to EF-Tu in EFR-expressing $N$. benthamiana suggests that the associated signaling components are conserved and that EFR is the surface PRR for EF-Tu (Zipfel et al., 2006). Interestingly, it was shown that EFR is required for basal defense against Agrobacterium tumefaciens, since Arabidopsis efr mutant plants permit more T-DNA integration into their genomes (Zipfel et al., 2006). This can also explain why the rate of Agrobacterium-mediated transformation is higher in $N$. benthamiana. 
Both FLS2 and EFR belong to typical leucine-rich repeat receptor-like kinases (LRR-RLKs). They interact with their cognate PAMPs through the extracellular LRR motif and initiate defense signaling via the intracellular protein kinase domain by phosphorylating an unknown substrate. Retained responsiveness of $f l s 2$ plants to EF-Tu and of efr plants to flagellin, respectively, indicates that FLS2 and EFR are separate sensory modules (Zipfel et al., 2006). However, flagellin and EF-Tu treatment renders the expression of the same gene populations in Arabidopsis, suggesting that their signalings are converged (Zipfel et al., 2006). Activation of the same MAP kinases by flagellin and EF-Tu (Zipfel et al., 2006) implies that the signaling convergence may occur at the upstream step of MAP kinase activation. Intrestingly, bacterial extracts are still able to mount defense activity in fls2 and efr mutant plants (Zipfel et al., 2004; 2006), suggesting that plants to detect bacterial pathogens possess more PRRs yet to be identified for bacterial PAMPs other than flagellin and EF-Tu.

Chitin is a rigidifying structural component of the fungal cell walls and is known to be a plant defense-triggering molecule. Recently, two chitin signaling-required proteins have been identified in plants. CEBiP, isolated by affinity chromatography in rice, binds chitin through the extracellular LysM motif that is found in many carbohydrateinteracting proteins (Kaku et al., 2006). In plants, the function of LysM motif as an oligosaccharide-binding module was revealed in the Nod factor receptors. The rhizobiaderived lipochitin-oligosaccharide, Nod factor is thought to be recognized by the extracellular LysM domain of Nod factor receptors in legume plants to initiate the symbiotic interactions (Limpens et al., 2003; Madsen et al., 2003; Radutoiu et al., 2003). Since silencing of CEBiP gene results in severe defect in the chitin responsiveness in rice (Kaku et al., 2006), it is regarded as an important component of chitin signaling. However, lack of the protein kinase domain suggests CEBiP as a co-receptor rather than a true receptor likely to amplify the chitin signal. On the basis of sequence similarity to CEBiP, CERK1 was identified as a key molecule in the chitin signaling in Arabidopsis (Miya et al., 2007; Wan et al., 2008). CERK1 however contains the intracellular protein kinase domain in addition to the extracellular LysM motif. Impaired defense activity of cerk1 mutant plants against fungal pathogens Alternaria brassicicola and Erysiphe cichoracearum (Miya et al., 2007; Wan et al., 2008) indeed supports its role in resistance to fungal pathogens. The direct binding of CERK1 to chitin (Iizasa et al., 2010) and loss of chitin responses in cerkl plants (Miya et al., 2007; Wan et al., 2008) suggest that CERK1 is a true Arabidopsis chitin PRR (Fig. 1).

$\beta$-glucan is the major constituent of the oomycetal and fungal cell walls, and has also long been known to elicit plant defense responses. Likely due to relatively weak responses, however a $\beta$-glucan-binding receptor has not been identified yet. Like the rice CEBiP, soybean glucan-binding protein (GBP) was isolated by affinity chromatography and originally proposed as a plant $\beta$-glucan PRR (Umemoto et al., 1997). However, GBP is lacking of a signal peptide to be secreted, the transmembrane (TM) motif and the intracellular protein kinase domain (Umemoto et al., 1997). Therefore, GBP is now regarded as a $\beta$-glucan-trimming enzyme for better recognition of $\beta$-glucan by a cognate PRR, since it has been recently shown to be secreted and possess a $\beta$-glucanase activity (Fliegmann et al., 2004).

Interestingly, it was recently reported that the activity of FLS2 and EFR is heightened by BAK1 (Chinchilla et al., 2007), a co-receptor of brassinosteroid signaling via interacting with BRI1 (Li et al., 2002; Nam and Li, 2002). Indeed, it is well known that the activation of $\mathrm{CD}^{+} \mathrm{T}$ cell requires the co-receptor $\mathrm{CD} 4$ to facilitate the interaction between the $\mathrm{T}$ cell receptor (TCR) and an antigen peptide presented by the major histocompatibility complex protein (MHC) in antigen-presenting cells (Kwon et al., 2008c). However, the affinity of FLS2 to flg22, the conserved minimum fragment of bacterial flagellin, in wild-type (WT) and bakl mutant plants is indistinguishable (Chinchilla et al., 2007). It seems therefore that BAK1 may modulate the signaling activity of FLS2 to amplify flagellin-stimulated signals for more powerful defense responses. In addition, the ligand-dependent interaction between FLS2 and BAK1 (Chinchilla et al., 2007) suggests that BAK1 acts as a molecular switch by changin its interacting partners depending on an external cue; FLS2 when stimulated by bacterial flagellin or BRI1 by brassinosteroid. Recently reported additional role of CERK1 in resistance to bacterial pathogens (Gimenez-Ibanez et al., 2009) also supports the importance of $\mathrm{PRR} /$ co-receptor or PRR/PRR coordination in plant defense responses.

Initiated defense signals by PRRs are then rapidly transduced via the MAP kinase cascade machinery to reprogram the infected cells (Asai et al., 2002). With this reprogramming, cells become competent to defend themselves against attempting pathogens by producing antimicrobials. Although animal immune cells utilize a few transcription factors such as NFkB and NFAT, plant cells depend on a large number of transcription regulators like WRKYs and TGA factors (Kwon et al., 2008c). Since the Arabidopsis genome contains $72 W R K Y$ and $10 T G A$ genes, it is likely that many WRKYs and TGAs work redundantly in the regulation defense gene expression. For example, WRKY18, 40 and 60 are highly homologous and comprise a distinct subgroup in the WRKY phylogenic tree (Eulgem et al., 2000). Through the Leu zipper domain, they interact with themselves and with each other. Interestingly, the affinity of WRKY18 to 
W-box (TTGACC/T), the binding site of WRKYs, was shown to be enhanced by interaction with WRKY40 or WRKY60 suggestive of their cooperative interactions. Consistently, the resistance to $P$. syringae pv. tomato DC3000, an Arabidopsis-pathogenic bacterium, becomes visibly compromised in wrky 18 wrky 40 wrky60 triple mutant plants compared to either single mutant (Xu et al., 2006). This strongly supports the redundant role of WRKYs in defense responses. Alternatively, there is also a possibility that WRKYs and TGAs are sub-functionalized in yet-unresolved small and particular defense reactions. Strikingly, it was recently reported that genes, whose expression is regulated by flagellin, EF-Tu and chitin, are overlapped (Wan et al., 2008), suggesting that at least these three signaling pathways are converged at an early point (Fig. 1). Although more plant PRRs must be identified and characterized, this may suggest that plant defense responses might be expressed through a common/shared signaling pathway.

Plants are able to spread alarming signal(s) from an infected site to become ready to protect yet uninfected tissues from pathogen attack. This phenomenon is called 'systemic acquired resistance (SAR)' and is known to be controlled by salicylic acid (SA), a key defense hormone (Durrant and Dong, 2004). Screening of mutants that fail to induce the expression of pathogenesis-related proteins (PRs) by SA revealed NPR1 as a central factor in SAR (Cao et al., 1994; Delaney et al., 1995; Cao et al., 1997; Ryals et al., 1997). NPR1 localizes to both cytosol and nucleus, but SA treatment or pathogen infection translocates NPR1 into the nucleus, leading to the induction of $P R$ genes expression (Kinkema et al., 2000). NPR1 proteins are present in the cytosol as high molecular oligomers that are unable to enter the nucleus (Mou et al., 2003). Recent biochemical and genetical analyses revealed that NPR1 forms a homo-oligomer via $S$-nitrosylation-mediated disulfide bonds and its monomer is released by thioredoxins (Tada et al., 2008). Constitutive release of NPR1 monomer results in NPR1 movement into the nucleus and subsequent induction of PRl in the absence of an inducer (Mou et al., 2003; Tada et al., 2008). Therefore, plant cells changes the intracellular redox status in response to pathogen infection to release NPR1 monomer from an oligomer and translocate NPR1 into the nucleus to induce the expression of defense-associated genes. TGA transcription factors bind the $P R 1$ promoter and these interactions are increased by SA treatment (Despres et al., 2000). Since TGAs interact with NPR1 and the enhanced binding of TGAs to PRI promoter is abolished in the absence of NPR1 (Despres et al., 2000; Zhang et al., 1999), NPR1 is suggested to regulate the expression of $P R$ genes via direct interaction with TGA transcription factors. The impaired induction of $P R I$ gene expression and the compromised resistance to $P$. syringae pv. tomato DC3000 only in tga2 tga5 tga6 triple mutant plants (Zhang et al., 2003) support the idea that TGAs function redundantly to transduce a defense signal from NPR1.

Plant cells have long been known to secrete numerous polypeptides and small molecules in response to pathogen attack (Kwon et al., 2008a). Representatives are PRs and secondary metabolites (Dixon, 2001; van Loon et al., 2006). However, the limited or little activity of a single member when overexpressed in transgenic plants strongly suggests that these secreted molecules work cooperatively as a cocktail in plant defense responses to restrict pathogen growth and terminate pathogenesis. So far, two distinct secretory pathways required for plant immune responses have been identified in Arabidopsis. One is an efflux-mediated secretion that involves the PEN2 peroxisome-associated glucosyl hydrolase and the PEN3 plasma membrane (PM)-residing ABC transporter (Lipka et al., 2005; Stein et al., 2006) (Fig. 1). Indole glucosinolate derivatives generated by PEN2 are supposed to be transported out via PEN3 (Bednarek et al., 2009), since both PEN2 and PEN3 are genetically placed in the same pathway. The involvement of PEN2 in the flagellin-triggered signaling through the indole glucosinolate metabolism (Clay et al., 2009) suggests multiple

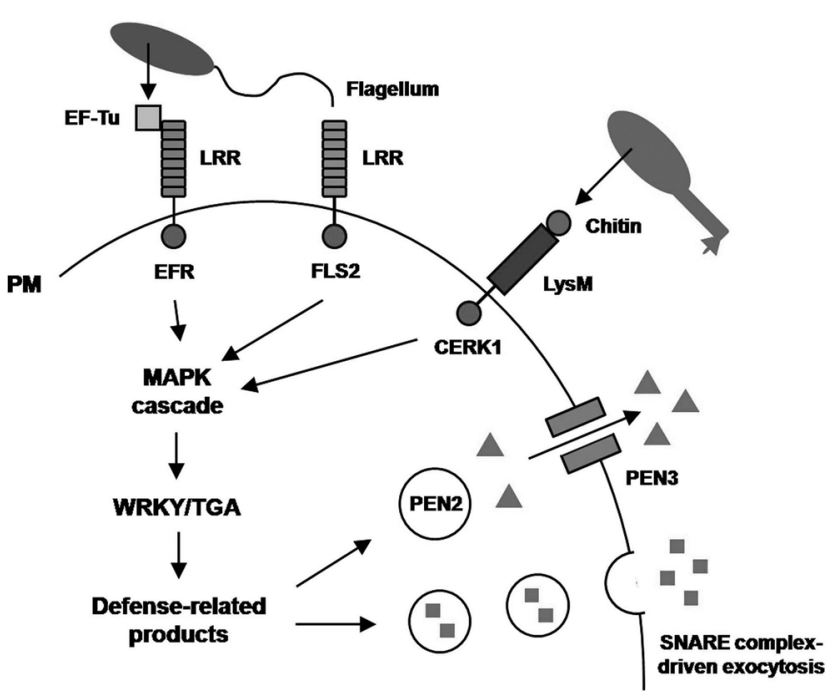

Fig. 1. A schematic view of current understanding of plant defense responses. Pathogen-derived non-self molecules, bacterial flagellin and EF-Tu and fungal chitin, are recognized cognate PRRs, FLS2, EFR and CERK1, respectively. This PAMP recognition drives infected host plant cells to reprogram by changing the gene expression patterns through the MAP kinase cascade. Plant defense-associated molecules such as PRs and secondary metabolites that are produced in response to pathogen attack are then secreted as a cocktail via the PEN2/PEN3 efflux pathway and/or the PEN1/SNAP33/VAMP721/722 exocytic pathway. 
functions of PEN2-hydrolyzed products of indole glucosinolates in plant immunity as a signaling component as well as the secreted antimicrobial.

The other identified secretory pathway is the SNARE complex-driven exocytosis that engages the PEN1 PMresisdent syntaxin, the SNAP33 adaptor and the vesicleassociated membrane proteins (VAMPs) 721/722 (Fig. 1). PEN1 gene was originally identified via screening of Arabidopsis mutants that allow more penetration of a nonadapted fungus, Blumeria graminis which normally fails to enter Arabidopsis epidermal cells (Collins et al., 2003). Subsequent study revealed that the PEN1 syntaxin forms SDS-resistant ternary SNARE complex with SNAP33 and VAMP721/722 (Kwon et al., 2008b). While PEN1 is involved in resistance only to non-adapted fungi such as $B$. graminis and E. pisi, VAMP721/722 are required for defense against the oomycete pathogen Hyaloperonospora parasitica, the adapted ascomycete Golovinomyces orontii as well as non-adapted fungi (Kwon et al., 2008b). This suggests that VAMP721/722 interact other PM syntaxins than PEN1 for resistance to $H$. parasitica and $G$. orontii. Interestingly, it was recently reported that in $N$. benthamiana NbSYP132 but not NbPEN1 is required for defense against the pathogenic bacterium $P$. syringae pv. tabaci expressing the AvrPto (Kalde et al., 2007). Correlation between down-regulation of NbSYP132 gene and delayed secretion of PRla (Kalde et al., 2007) suggests that VAMP721/722 interact with and form ternary SNARE complex with SYP132 rather than PEN1 for disease resistance to the bacterial pathogen, because it was recently found that depletion of VAMP721/722 in Arabidopsis allows more growth of $P$. syringae pv. tomato DC3000 (Yun and Schulze-Lefert, unpublished data).

Delayed focal deposition of callose, a component of inducible cell walls called papilla at fungal penetration sites, in both pen1 and VAMP721/722-depleted plants (Assaad et al., 2004; Kwon et al., 2008b) suggests cell wall building blocks and/or cell wall-modifying enzymes as potential cargo delivered and released via the PEN1SANP33-VAMP721/722 secretory pathway. More susceptibility of the VAMP721/722-depleted plants to the virulent oomycete $H$. parasitica and the adapted ascomycete $G$. orontii (Kwon et al., 2008b) indicates that the VAMP721/ 722 vesicles transport additional antimicrobial cargo. Interestingly, all secretory machinery proteins mentioned above are focally concentrated at pathogen-contacting sites (Kwon et al., 2008c). This conceptually similar mechanism to focal secretion seen in activated animal $\mathrm{T}$ cells proposes that plant cells also focally release out antimicrobials to more effectively kill the parasites with undiluted high concentration and/or to protect themselves from damage by their own toxic cargo.

\section{Acknowledgement}

This work was supported by 2009 Research Fund of Dankook University (84604).

\section{References}

Asai, T., Tena, G., Plotnikova, J., Willmann, M. R., Chiu, W. L., Gomez-Gomez, L., Boller, T., Ausubel, F. M. and Sheen, J. 2002. MAP kinase signalling cascade in Arabidopsis innate immunity. Nature 415:977-983.

Assaad, F. F., Qiu, J. L., Youngs, H., Ehrhardt, D., Zimmerli, L., Kalde, M., Wanner, G., Peck, S. C., Edwards, H., Ramonell, K., Somerville, C. R. and Thordal-Christensen, H. 2004. The PEN1 syntaxin defines a novel cellular compartment upon fungal attack and is required for the timely assembly of papillae. Mol. Biol. Cell 15:5118-5129.

Bednarek, P., Pislewska-Bednarek, M., Svatos, A., Schneider, B., Doubsky, J., Mansurova, M., Humphry, M., Consonni, C., Panstruga, R., Sanchez-Vallet, A., Molina, A. and SchulzeLefert, P. 2009. A glucosinolate metabolism pathway in living plant cells mediates broad-spectrum antifungal defense. Science 323:101-106.

Boller, T. and He, S. Y. 2009. Innate immunity in plants: an arms race between pattern recognition receptors in plants and effectors in microbial pathogens. Science 324:742-744.

Cao, H., Bowling, S. A., Gordon, A. S. and Dong, X. 1994. Characterization of an Arabidopsis Mutant That Is Nonresponsive to Inducers of Systemic Acquired Resistance. Plant Cell 6: 1583-1592.

Cao, H., Glazebrook, J., Clarke, J. D., Volko, S. and Dong, X. 1997. The Arabidopsis NPR1 gene that controls systemic acquired resistance encodes a novel protein containing ankyrin repeats. Cell 88:57-63.

Chinchilla, D., Zipfel, C., Robatzek, S., Kemmerling, B., Nurnberger, T., Jones, J. D., Felix, G and Boller, T. 2007. A flagellin-induced complex of the receptor FLS2 and BAK1 initiates plant defence. Nature 448:497-500.

Clay, N. K., Adio, A. M., Denoux, C., Jander, G and Ausubel, F. M. 2009. Glucosinolate metabolites required for an Arabidopsis innate immune response. Science 323:95-101.

Collins, N. C., Thordal-Christensen, H., Lipka, V., Bau, S., Kombrink, E., Qiu, J. L., Huckelhoven, R., Stein, M., Freialdenhoven, A., Somerville, S. C. and Schulze-Lefert, P. 2003. SNARE-protein-mediated disease resistance at the plant cell wall. Nature 425:973-977.

Dallo, S. F., Kannan, T. R., Blaylock, M. W. and Baseman, J. B. 2002. Elongation factor Tu and E1 beta subunit of pyruvate dehydrogenase complex act as fibronectin binding proteins in Mycoplasma pneumoniae. Mol. Microbiol. 46:1041-1051.

Delaney, T. P., Friedrich, L. and Ryals, J. A. 1995. Arabidopsis signal transduction mutant defective in chemically and biologically induced disease resistance. Proc. Natl. Acad. Sci. USA 92:6602-6606.

Despres, C., DeLong, C., Glaze, S., Liu, E. and Fobert, P. R. 2000. The Arabidopsis NPR1/NIM1 protein enhances the DNA 
binding activity of a subgroup of the TGA family of bZIP transcription factors. Plant Cell 12:279-290.

Dixon, R. A. 2001. Natural products and plant disease resistance. Nature 411:843-847.

Durrant, W. E. and Dong, X. 2004. Systemic acquired resistance. Annu. Rev. Phytopathol. 42:185-209.

Eulgem, T., Rushton, P. J., Robatzek, S. and Somssich, I. E. 2000. The WRKY superfamily of plant transcription factors. Trends Plant Sci. 5:199-206.

Fliegmann, J., Mithofer, A., Wanner, G and Ebel, J. 2004. An ancient enzyme domain hidden in the putative beta-glucan elicitor receptor of soybean may play an active part in the perception of pathogen-associated molecular patterns during broad host resistance. J. Biol. Chem. 279:1132-1140.

Gimenez-Ibanez, S., Hann, D. R., Ntoukakis, V., Petutschnig, E., Lipka, V. and Rathjen, J. P. 2009. AvrPtoB targets the LysM receptor kinase CERK1 to promote bacterial virulence on plants. Curr. Biol. 19:423-429.

Gomez-Gomez, L. and Boller, T. 2000. FLS2: an LRR receptorlike kinase involved in the perception of the bacterial elicitor flagellin in Arabidopsis. Mol. Cell 5:1003-1011.

Granato, D., Bergonzelli, G E., Pridmore, R. D., Marvin, L., Rouvet, M. and Corthesy-Theulaz, I. E. 2004. Cell surface-associated elongation factor Tu mediates the attachment of Lactobacillus johnsonii NCC533 (La1) to human intestinal cells and mucins. Infect. Immun. 72:2160-2169.

Iizasa, E., Mitsutomi, M. and Nagano, Y. 2010. Direct binding of a plant LysM receptor-like kinase, LysM RLK1/CERK1, to chitin in vitro. J. Biol. Chem. 285:2996-3004.

Kaku, H., Nishizawa, Y., Ishii-Minami, N., Akimoto-Tomiyama, C., Dohmae, N., Takio, K., Minami, E. and Shibuya, N. 2006. Plant cells recognize chitin fragments for defense signaling through a plasma membrane receptor. Proc. Natl. Acad. Sci. USA 103:11086-11091.

Kalde, M., Nuhse, T. S., Findlay, K. and Peck, S. C. 2007. The syntaxin SYP132 contributes to plant resistance against bacteria and secretion of pathogenesis-related protein 1. Proc. Natl. Acad. Sci. USA 104:11850-11855.

Kinkema, M., Fan, W. and Dong, X. 2000. Nuclear localization of NPR1 is required for activation of PR gene expression. Plant Cell 12:2339-2350.

Kunze, G, Zipfel, C., Robatzek, S., Niehaus, K., Boller, T. and Felix, G 2004. The N terminus of bacterial elongation factor $\mathrm{Tu}$ elicits innate immunity in Arabidopsis plants. Plant Cell 16:3496-3507.

Kwon, C., Bednarek, P. and Schulze-Lefert, P. 2008a. Secretory pathways in plant immune responses. Plant Physiol. 147: 1575-1583.

Kwon, C., Neu, C., Pajonk, S., Yun, H. S., Lipka, U., Humphry, M., Bau, S., Straus, M., Kwaaitaal, M., Rampelt, H., El Kasmi, F., Jurgens, G, Parker, J., Panstruga, R., Lipka, V. and Schulze-Lefert, P. 2008b. Co-option of a default secretory pathway for plant immune responses. Nature 451:835-840.

Kwon, C., Panstruga, R. and Schulze-Lefert, P. 2008c. Les liaisons dangereuses: immunological synapse formation in animals and plants. Trends Immunol. 29:159-166.
Li, J., Wen, J., Lease, K. A., Doke, J. T., Tax, F. E. and Walker, J. C. 2002. BAK1, an Arabidopsis LRR receptor-like protein kinase, interacts with BRI1 and modulates brassinosteroid signaling. Cell 110:213-222.

Limpens, E., Franken, C., Smit, P., Willemse, J., Bisseling, T. and Geurts, R. 2003. LysM domain receptor kinases regulating rhizobial Nod factor-induced infection. Science 302:630-633.

Lipka, V., Dittgen, J., Bednarek, P., Bhat, R., Wiermer, M., Stein, M., Landtag, J., Brandt, W., Rosahl, S., Scheel, D., Llorente, F., Molina, A., Parker, J., Somerville, S. and Schulze-Lefert, P. 2005. Pre- and postinvasion defenses both contribute to nonhost resistance in Arabidopsis. Science 310:1180-1183.

Madsen, E. B., Madsen, L. H., Radutoiu, S., Olbryt, M., Rakwalska, M., Szczyglowski, K., Sato, S., Kaneko, T., Tabata, S., Sandal, N. and Stougaard, J. 2003. A receptor kinase gene of the LysM type is involved in legume perception of rhizobial signals. Nature 425:637-640.

Melotto, M., Underwood, W., Koczan, J., Nomura, K. and He, S. Y. 2006. Plant stomata function in innate immunity against bacterial invasion. Cell 126:969-980.

Miya, A., Albert, P., Shinya, T., Desaki, Y., Ichimura, K., Shirasu, K., Narusaka, Y., Kawakami, N., Kaku, H. and Shibuya, N. 2007. CERK1, a LysM receptor kinase, is essential for chitin elicitor signaling in Arabidopsis. Proc. Natl. Acad. Sci. USA 104:19613-19618.

Mou, Z., Fan, W. and Dong, X. 2003. Inducers of plant systemic acquired resistance regulate NPR1 function through redox changes. Cell 113:935-944.

Nam, K. H. and Li, J. 2002. BRI1/BAK1, a receptor kinase pair mediating brassinosteroid signaling. Cell 110:203-212.

Radutoiu, S., Madsen, L. H., Madsen, E. B., Felle, H. H., Umehara, Y., Gronlund, M., Sato, S., Nakamura, Y., Tabata, S., Sandal, N. and Stougaard, J. 2003. Plant recognition of symbiotic bacteria requires two LysM receptor-like kinases. Nature 425:585-592.

Ryals, J., Weymann, K., Lawton, K., Friedrich, L., Ellis, D., Steiner, H. Y., Johnson, J., Delaney, T. P., Jesse, T., Vos, P. and Uknes, S. 1997. The Arabidopsis NIM1 protein shows homology to the mammalian transcription factor inhibitor I kappa B. Plant Cell 9:425-439.

Stein, M., Dittgen, J., Sanchez-Rodriguez, C., Hou, B. H., Molina, A., Schulze-Lefert, P., Lipka, V. and Somerville, S. 2006. Arabidopsis PEN3/PDR8, an ATP binding cassette transporter, contributes to nonhost resistance to inappropriate pathogens that enter by direct penetration. Plant Cell 18:731-746.

Tada, Y., Spoel, S. H., Pajerowska-Mukhtar, K., Mou, Z., Song, J., Wang, C., Zuo, J. and Dong, X. 2008. Plant immunity requires conformational changes [corrected] of NPR1 via S-nitrosylation and thioredoxins. Science 321:952-956.

Umemoto, N., Kakitani, M., Iwamatsu, A., Yoshikawa, M., Yamaoka, N. and Ishida, I. 1997. The structure and function of a soybean beta-glucan-elicitor-binding protein. Proc. Natl. Acad. Sci. USA 94:1029-1034.

van Loon, L. C., Rep, M. and Pieterse, C. M. 2006. Significance of inducible defense-related proteins in infected plants. Anпu. Rev. Phytopathol. 44:135-162. 
Wan, J., Zhang, X. C., Neece, D., Ramonell, K. M., Clough, S., Kim, S. Y., Stacey, M. G and Stacey, G. 2008. A LysM receptor-like kinase plays a critical role in chitin signaling and fungal resistance in Arabidopsis. Plant Cell 20:471-481.

Xu, X., Chen, C., Fan, B. and Chen, Z. 2006. Physical and functional interactions between pathogen-induced Arabidopsis WRKY18, WRKY40, and WRKY60 transcription factors. Plant Cell 18:1310-1326.

Zhang, Y., Fan, W., Kinkema, M., Li, X. and Dong, X. 1999. Interaction of NPR1 with basic leucine zipper protein transcription factors that bind sequences required for salicylic acid induction of the PR-1 gene. Proc. Natl. Acad. Sci. USA 96:
6523-6528.

Zhang, Y., Tessaro, M. J., Lassner, M. and Li, X. 2003. Knockout analysis of Arabidopsis transcription factors TGA2, TGA5, and TGA6 reveals their redundant and essential roles in systemic acquired resistance. Plant Cell 15:2647-2653.

Zipfel, C., Kunze, G., Chinchilla, D., Caniard, A., Jones, J. D., Boller, T. and Felix, G. 2006. Perception of the bacterial PAMP EF-Tu by the receptor EFR restricts Agrobacteriummediated transformation. Cell 125:749-760.

Zipfel, C., Robatzek, S., Navarro, L., Oakeley, E. J., Jones, J. D., Felix, G and Boller, T. 2004. Bacterial disease resistance in Arabidopsis through flagellin perception. Nature 428:764-767. 